\title{
MEDICATION ERRORS AND DRUG-DISPENSING SYSTEMS IN A HOSPITAL PHARMACY
}

Tânia Azevedo Anacleto, Edson Perini, Mário Borges Rosa, and Cibele Comini

César

Anacleto TA, Perini E, Rosa MB, César CC. Medication errors and drug-dispensing systems in the hospital pharmacy. Clinics. 2005;60(4):325-32.

Pharmacies permeate and interconnect various actions developed in different sectors within the complex process of the use of drugs in a hospital. Dispensing failures mean that a breach has occurred in one of the last safety links in the use of drugs. Although most failures do not harm patients, their existence suggests fragility in the process and indicates an increased risk of severe accidents. Present concepts on drug-related incidents may be classified as side effects, adverse effects, and medication errors. Among these are dispensing errors, usually associated with poor safety and inefficient dispensing systems. Factors associated with dispensing errors may be communication failures, problems related to package labels, work overload, the physical structure of the working environment, distraction and interruption, the use of incorrect and outdated information sources and the lack of patient knowledge and education about the drugs they use. So called banal dispensing errors reach significant epidemiological levels. The purpose of this paper, which is part of a study on the occurrence of dispensing errors in the pharmacy of a large hospital, is to review the main concepts that guide studies on adverse effects and to provide an update on dispensing errors.

\section{KEYWORDS: Medication errors. Dispensing errors. Drugs. Pharmacy. Adverse effects.}

Risk associated with medical drugs, one of the main tools used today to protect, maintain and restore health, have increased. The onset of adverse effects, with its damaging consequences for patients, health professionals, and health institutions, is reason for concern in most health-related sectors. This concern, in fact, is linked to the origin itself of therapeutics. The archaic Greek word pharmakon meant a sacrifice made to the gods to seek a cure, and bore a double meaning: remedy and poison. ${ }^{1,2}$

Drug safety is not a static concept. The perception of what is acceptable as risk or benefit together with safety evidence requirements has radically changed during the $20^{\text {th }}$ century, in tune with therapeutic developments and the re-

Faculty of Pharmacy, Federal University of Minas Gerais - Belo Horizonte/ MG, Brazil.

E-mail:taniaanacleto@yahoo.com

Received for publication on October 07, 2004.

Accepted for publication on April 29, 2005. sulting disasters related to such developments. ${ }^{2}$ In the United Sates of America, the accident in 1937 with a sulfanilamide elixir containing diethylglycol as an excipient (the toxicity of which had already been documented) led, in 1938, to the first law requiring toxicity assays in order to authorize the sale of new drugs. This law changed the charter of the Food and Drug Administration (FDA) which began to assess drug safety prior to their entry into the market. Many European countries created drug control agencies that wrote their own specific regulations. ${ }^{2-4}$

The thalidomide-induced phocomelia episode in the late 1950 s and early 1960 s affected some 4,000 people worldwide and may be considered a major landmark in the development of legislation on drugs in most European countries. This has introduced a new era in the control of drug-induced adverse effects, marked by the diversification and expansion of regulating and monitoring mechanisms. ${ }^{3,4}$ The thalidomide tragedy also led to the development of drug surveillance as a set of activities for detecting and as- 
sessing adverse effects of drugs that were already in the market. In 1964 England implemented the "yellow card" system, which became the basis for the World Health Organization (WHO) international voluntary communication program. ${ }^{2}$

Significant methodological changes in surveillance studies of adverse effects were implemented in the 1990s. These changes reflect the recognition that drugs may also produce harmful effects due to failures and errors during the clinical use ${ }^{2}$ in addition to the intrinsic risks of adverse effects due to their use under appropriate conditions.

Manasse ${ }^{5,6}$ published an analysis of studies on drug incidents highlighting the fact that the use of these drugs is not perfect throughout the whole sequence of actions and decisions that cover the drug-use chain of events. Medication errors occur in prescription, dispensing, and delivery, all of which may help to increase the harmful potential of drugs. These errors may be caused by experienced or inexperienced staff, including pharmacists, medical doctors, nurses, assistants, patients, or their caretakers.

A meta-analysis of 39 prospective studies conducted in North-American hospitals between 1966 and 1996 found that the incidence of drug-related adverse effects was extremely high. An estimate for North America in 1994 was that approximately 2,216,000 hospital patients had severe adverse drug reactions and 106,000 people died as a consequence of such reactions. These results placed drug-related adverse reactions as the $5^{\text {th }}$-leading cause of death. ${ }^{7}$ In 1999 the Committee on Quality of Health Care in America report highlighted the fact that medication errors cause over 7,000 deaths per year and result in adverse effects in $2 \%$ of in-hospital patients. The report also suggested that medication errors increased the cost of each hospital stay by US 4,700 , resulting in an annual cost of billions of dollars if these values extrapolated to the entire country. ${ }^{8,9}$

Errors in health establishments are complicated situations, particularly in hospitals, where patients are away from their family and social environment to seek healthcare. Human failure in a hospital, when detected, usually causes health professionals to fear sanctions, loss of prestige, and shame vis à vis their peers, as well as being a challenge to professional competence. ${ }^{10}$

Factors determining medication errors may be generated during the drug dispensing process within a hospital, where pharmacy activities guide many of the actions associated with patient assistance. This paper deals with the main concepts guiding present studies on adverse effects, the main characteristics of different hospital drug-dispensing systems, their relationship with the occurrence of medication errors, and the main predisposing factors and associated conditions related to dispensing errors. The review sought to identify the origins of this theme in the scientific literature during the mid-twentieth century and the most significant papers published since that time.

\section{CONCEPTS}

According to the National Coordinating Council for Medication Error Reporting and Prevention (NCCMERP), drug-related incidents may be classified into groups and include adverse reactions, adverse effects, and medication errors. ${ }^{11}$ There is still much controversy regarding these concepts; consequently a brief review of the most accepted terminology at present is given below:

- A drug-related adverse effect is defined as mild, moderate, or severe damage caused by the use or non-use of a drug. It may be classified as avoidable or unavoidable. ${ }^{12}$

- An adverse reaction to drugs is defined as every harmful and undesirable effect occurring after a drug is administered in doses usually used by man for prophylaxis, diagnosis, or treatment of a disease or with the aim of changing a biological function. ${ }^{13}$

- Medication error is defined as any avoidable event that may harm the patient as a result of an inappropriate use of drugs when these are given under the control of health professionals or patients. These events may be related to professional practice and/or to health care procedures or systems, including prescription failures, drug naming, preparation, dispensing, distribution, delivery, education, follow-up, and use. Medication errors may or may not result in an adverse effect; many errors do not cause damage or injury, but indicate a low level of safety in health assistance. ${ }^{2,11}$

- Dispensing error is defined as the discrepancy between the written order in a medical prescription and the following of this order. These errors are made by pharmacy staff (including pharmacists) when dispensing drugs to hospital units. ${ }^{14,15}$ Dispensing errors are also a type of medication error, as are drug delivery errors, and prescription errors.

The possibility of prevention is a significant difference between adverse effects and medication errors. Drug adverse effects are unavoidable events, notwithstanding their probable occurrence, whereas medication errors are by definition avoidable, meaning failure in use. ${ }^{10}$ Furthermore, harm characterizes the adverse effect, while an error may be defined as a potentially harmful incident.

\section{DRUG-DISPENSING SYSTEMS IN HOSPITALS}

Drugs are one of the main tools of medical therapy and are a significant part of hospital budgets. Implementing 
safe, organized, and efficient drug-dispensing systems is essential for controlling costs and assuring that the medical prescription is safely followed as requested within the appropriate deadline. An appropriate dispensing system is an important ally for the prevention or reduction of medication errors by helping to minimize dispensing error opportunities in a pharmacy. At present there are various types of dispensing systems for medical prescriptions within a hospital.

The first studies on the organization of such systems, specifically their relationship with medication errors, were published in the mid-sixties. These studies mostly performed in the United States of America were intensified during the 1970s and 1980s, aiming to provide safer dispensing systems. Investigation in this area in Brazil was started during the1990s and is still not numerically significant.

\section{Collective System}

The collective system, also known as the traditional system, is the oldest and most obsolete. In this system, drugrelated actions are centered on nursing professionals, and the pharmacy is merely a drug delivery agent. This system has many facilitating conditions for errors. It is characterized by the distribution of drugs per hospital unit/service based on a request by a nurse. It implies the establishment of inventory in these units under the nurse's supervision. ${ }^{16,17}$

It is estimated that nurses spend about $25 \%$ of their time transcribing prescriptions, checking inventory, filling requests, and transporting and separating drugs in the various units. Institutional costs are high due to losses by theft, inadequate storage, and drug expiration. ${ }^{17,18}$

The advantages of this system are that drugs are readily available at the units, there are fewer requests to the pharmacy, with a corresponding reduction in pharmacy expenses related to human resources and materials. These advantages become obstacles for improved pharmaceutical service to patients. ${ }^{17}$ A negative consequence is a high rate of medication errors, the most common being giving twice the dosage, giving the wrong drug, inappropriate dose and administration routes, and giving non-prescribed drugs. A further disadvantage is inefficient stock control and increased expenses related to drugs. ${ }^{16,18,19}$

According to the first pharmacy assessment in Brazil in $2002,51.2 \%$ of hospital pharmacies use the collective drugdispensing system. ${ }^{20}$

\section{Individualized System}

In the individualized drug-dispensing system, the pharmacy and pharmacists participate more actively on drug- use issues; however, nursing participation and error rates are still high. In this system, drugs are dispensed per patient, usually for a 24-hour treatment period. The pharmacy dispenses drugs separately per patient, according to the medical prescription, to the hospital units. ${ }^{16,17}$ In Brazil, $34.8 \%$ of hospitals use this drug-dispensing system for inhospital patients. ${ }^{20}$

This system may be described as indirect, where drug dispensing is based on a transcription of the medical prescription made by nurses, or direct, where dispensing is based on a copy of the medical prescription (made daily). The indirect system has a high rate of errors and theft, as failure and omission may take place during transcription and items not present in the original prescription may be added.

In the direct system, the prescription may be forwarded to the pharmacy as follows ${ }^{17}$ :

a) the prescription is written over carbon paper to produce a copy of the original. Poor quality carbon paper or inadequate pens may result in prescription copies that are difficult to read;

b) photocopy to reproduce the original prescription;

c) fax from the hospital unit to the pharmacy. This method may generate illegible documents, opening the door for new sources of medication errors and allowing loss of information with time;

d) the physician writes the prescription on computer terminals in the hospital unit and sends it electronically to the pharmacy. The main advantage is the elimination errors due to poor handwriting. However, other types of errors may appear, such as printing the prescription made the previous day or not saving changes, resulting in wrong prescriptions. Also the prescriptions of 2 or more patients may be accidentally exchanged;

e) computerized prescription: using clinical management software interconnecting the various hospital units. The prescription and the dispensing report are made in the system that may be integrated with pharmacology and inventory control software. Professionals access system data directly with no need to send files. There are also safety systems that warn against toxic doses, allergic and cross-reactions, drug interactions, duplication of therapeutic classes, contraindications, and adverse effects. Automation using bar codes allows drugs to be checked when dispensing and administering the drug;

f) radio system interconnecting computers and optic readers: the physician uses a small electronic pen-operated or touch-sensitive terminal, allowing immediate checking of patient data, rapid prescription (at the bedside), and fewer computers in hospital units.

The individualized drug-dispensing system has advan- 
tages, such as the possibility of reviewing medical prescriptions, increased control over drug use, less inventory in hospital units, reduced theft and losses, and individual patient invoicing. The disadvantages are the high rates of dispensing and delivery errors that still exist, the time spent by nurses calculating and preparing drug doses, increased expense regarding human resources and materials, and high losses due to theft and inadequate drug delivery. ${ }^{16,17}$

Usually, the pharmacy is present in hospital units. Pharmacy assistants replenish emergency stocks daily, collect prescriptions for the day, collect drugs returned from the previous day, and send drugs for the following 24 hours of treatment. On a monthly basis they also check drug validity in the inventory and unauthorized inventory. Pharmacists visit hospital units daily to supervise work done by their assistants. They also help nurses clarify doubts related to drug delivery and stability as well as storage and use of heat-sensitive and photo-sensitive drugs. Pharmacists also discuss prescription issues with physicians. In hospitals with adequate human resources allied to professional and institutional interests, pharmacists develop clinical activities with the professional health team to reduce medication errors.

\section{Mixed System}

The mixed dispensing system combines the collective and the individualized systems and is also used in Brazilian hospitals. Hospital units are supported partially or completely by the individualized systems, and specific units (radiology, endoscopy, emergency, outpatient department, among others) are supported by the collective system. ${ }^{17}$ The mixed system is used by $13.2 \%$ of Brazilian hospitals for dispensing drugs. ${ }^{20}$

The main disadvantage of the mixed system is a trend towards the collective rather than the individualized system, favoring drug dispensing by hospital unit rather than per patient dispensing. It is easier to dispense drugs by hospital unit instead of separating and packaging items for each patient. Pharmacy staff should be made aware of the importance of their work and that collective dispensing is easier but not as safe.

\section{Unit dose system}

Drug administration in hospitals may involve 20 to 30 steps from prescription to delivery and monitoring. During the past 50 years, little has changed in this process except for the development and implementation of the unit dose drug-dispensing system. ${ }^{21}$

The high rate of medication errors in hospitals reported in many North-American studies towards the end of the 1950s, demonstrated the need to review traditional dispensing systems to improve safety in drug dispensing and delivery. In 1960, North-American hospital pharmacists belonging to a multidisciplinary group developed the unit dose system, aiming to reduce medication error rates, drug costs, losses and theft, and to improve the productivity of health professionals and the quality of health care. This system consists of ordered drug dispensing with doses ready for delivery according to the patient's medical prescription. Every drug, in all pharmaceutical forms, is dispensed readyto-use with no need for prior transference, calculation, and handling by nurses. Only drugs used in emergencies are stored in hospital units, together with the necessary doses for the next 24 hours of treatment of patients. ${ }^{16,17}$

The system has the following advantages: drug identification right up to the moment of delivery; lower medication error rates; less nursing time spent on drug handling, increased nurse availability for patient care; less inventory in units, with decreased losses; optimizing the return of unused drugs; better hospital infection control through the practice of aseptic techniques in the preparation of drug doses; increased adaptability for automation; increased precision in invoicing drug use per patient; increased assurance for physicians that the prescription will be administered; effective pharmacist participation in defining drug therapy; improved control over the pattern and time of drug delivery; less space used to keep drugs in hospital units; and improved patient assistance. The disadvantages are resistance by nurses to the system, the need for extra staff and pharmacy infrastructure, the need to acquire specific equipment, and a high initial financial investment. ${ }^{16,17}$ Furthermore, pharmacists need to be trained to prepare parenteral drugs, knowledge not imparted by the majority of pharmacy colleges in Brazil.

Implementation of this system in Brazil is a huge challenge. Only $0.4 \%$ of hospitals use it to dispense drugs. ${ }^{20}$ The initial investment to acquire specific equipment for a sterile product-preparation center is high and not within the reach of small and mid-sized institutions, which represent more than $80 \%$ of Brazilian hospitals. ${ }^{17}$

\section{DISPENSING SYSTEMS AND MEDICATION ERRORS}

Mid-20 ${ }^{\text {th }}$ century studies showed that the traditional drug-dispensing systems (collective and/or individualized) on average resulted in 1 wrong delivery for each 6 doses delivered to patients. The causes of these errors included poor handwriting quality, errors in transcribing the prescription, the use of non-standard abbreviations, different weights and measures systems adopted within the same hospital, verbal medical order, incomplete or con- 
fusing prescriptions, failure in communicating discontinuation of prescribed drugs, lack of knowledge about drug stability, incompatible associations and inadequate storage by nurses, similar trade and generic names, and difficulties for nurses in correlating the generic and trade name nomenclature. ${ }^{22,23}$

A study in 1965 compared the incidence of medication errors in hospitals using different dispensing systems, and the results showed a significant reduction in medication error rates with the unit dose system. Detected errors, comparing drug prescription and delivery, were reduced from $31.2 \%$ to $13.4 \%$ (a $57 \%$ reduction). The new system increased pharmacist participation in drug control and distribution by $39.4 \%$, and nursing time involved with the handling of drugs was reduced by $13.7 \%$. The dispensing error rate reported in the unit dose system was 3.8\%. ${ }^{24} \mathrm{~A}$ further North-American study in 1969 comparing the traditional and the unit dose dispensing systems found a $50 \%$ reduction in nursing time involved with drug use and control, and a drastic reduction in the medication error rate, from $26 \%$ to $2 \% .^{25}$

North-American, British, and Canadian studies in the n1970s and 1980s in hospitals not adopting the unit dose dispensing system found a rate of medication error of 1 per patient/day. Hospitals using unit doses may reduce error rates to around 2 or 3 errors per patient/week, as found in a 1983 study. Another study conducted during 23 days in 1994 compared dispensing error rates in work environments with varying interruption levels, distractions, noise, and work overload, and found that error rates were $3.23 \%$ and $1.23 \%$ in environments with higher and lower levels of these variables, respectively. ${ }^{26,27}$ Table 1 presents the 3 studies found in the literature comparing medication error rates in different dispensing systems.

Table 1- Medication errors in different drug-dispensing systems

\begin{tabular}{|c|c|c|}
\hline \multirow{2}{*}{ Published } & \multicolumn{2}{|c|}{$\begin{array}{l}\text { Medication errors according to } \\
\text { the drug dispensing system }\end{array}$} \\
\hline & Traditional* & Unit Dose \\
\hline 1969 & $31.2 \%$ & $13.4 \%$ \\
\hline Crawley, 1971 & $26.0 \%$ & $2 \%$ \\
\hline Barker, 1984 & 1 error/patient/day & 1 error/patient/week \\
\hline
\end{tabular}

* Collective, Individualized

A 1999 study in a Brazilian hospital based on reports of situations associated with drug delivery errors noted that $26.8 \%$ of procedures had errors related to failures in the dispensing system and drug preparation. Failures included delays in the delivery time, drugs with similar labels and pack- ages, many drugs at the same time with resulting delays in drug administration, and drugs sent with the wrong presentation. One of the reports is a good example of how a dispensation error can lead to a drug administration error: “... it was an intravenous drug that came from the pharmacy, it was supposed to be PO, but as it came in ampoules, I administered it IV.....28

\section{FACTORS ASSOCIATED WITH DISPENSING ERRORS: CAUSES AND CONSEQUENCES}

Concern with determining factors of medication errors is not recent. A 1939 study had reported errors by nurses in a teaching hospital, the most common of which was delivery of the wrong drug and drug administration to the wrong patient. Factors most frequently associated with errors were failures when reading the prescription, lack of attention, forgetfulness, and inadequate patient identification. ${ }^{29}$

Today there are many known factors causing dispensing errors. Knowledge about them facilitates operational procedures for efficient and safe practices. The most common causes of these errors are associated with the unsafe and inefficient nature of dispensing systems and other factors directly connected with drug dispensing and delivery (Table 2). According to Cohen, ${ }^{14}$ these factors may be summarized as communication failures, issues relating to drug labeling and packaging, work overload and the structure of the work area, distractions and interruptions, incorrect or outdated sources of information, and lack of knowledge and education of patients on the drugs delivered to them. These factors are listed and discussed below:

\section{Communication failures}

The prescription is responsible for conveying information about the prescribed drug and its usage in a way that anyone reading it may fully understand the instructions. Ambiguous, incomplete, or confusing prescriptions may lead to poor understanding of fundamental information for correct drug dispensing and delivery.

Prescription readability problems are well known as a cause of medication errors. A prescription should be easily read rather than interpreted. This situation may lead to errors and cause injury or even death for patients. In 1997, the American Medical Association stated that errors resulting from poorly interpreted prescriptions were the second most prevalent complaint and the most expensive in a list containing 90,000 complaints over 7 years. ${ }^{4,14}$ A study in a Brazilian university hospital noted that nurses considered readability problems to be the fourth most important cause of drug delivery errors. ${ }^{30}$ 
Table 2 - Causes of dispensing errors and contributing factors associated with dispensing systems*

\section{CAUSES OF DISPENSING ERRORS}

1. Communication failures

1.1 ambiguous, incomplete or confusing prescriptions

1.2 unreadable prescriptions

1.3 similarity (phonetic and/or orthographic) of drug names

2. Problems related to drug labeling and packaging 2.1 similar labels and packages in size, shape, and color

3. Working environment and conditions

3.1 inadequate space

3.2 poor lighting

3.3 high temperatures

3.4 inadequate drug storage

3.5 work overload

3.6 little time for drug dispensing

4. Drug information

4.1 lack of health professional and patient knowledge about drugs

4.2 using outdated drug information

\section{CONTRIBUTING FACTORS ASSOCIATED WITH DISPENSING} SYSTEMS

1. Collective system

1.1 actions centered on nursing professionals

1.2 drug dispensing through requests by nurses

1.3 failures in transcribing medical prescriptions

1.4 pharmacists participate poorly in drug-related issues

1.5 high rates of medication errors

2. Individualized system

2.1 problems in reading copies of the medical prescription (depending on the type of copy)

2.2 failures in following dispensing guidelines

2.3 high dispensing error rates

3. Unit dose system

3.1 lack of trained professionals to prepare parenteral mixtures 3.2 lack of specific equipment to prepare parenteral mixtures

* Adapted from Otero MJ, Martín R, Robles MD, Codina C. Errores de medicación. Madrid: Farmacia Hospitalaria, 2002, 747p.

Manual writing may complicate the distinction between 2 drugs with similar names. Many drugs have similar names or drug names may sound similar, leading to confusion, particularly when they are delivered through the same route or have similar dosages. Dispensing of the drug Plendil (felodipine) in place of Isordil (isosorbide) due to poor prescription readability in a North-American pharmacy involved the pharmacist, the pharmacy, and the physician in a lawsuit as being responsible for the death of a patient who had an acute myocardial infarction after taking the wrong drug. Similar drug names are responsible for over one third of medication errors reported in the United States Pharmacopoeia Medication Errors Reporting Program (USPMERP). Confusion may happen with both generic and trade names. $^{14}$

\section{Problems related to drug labeling and packaging}

Problems related to drug labeling and packaging are the second most reported category in the most frequent medication errors reported to the USP-MERP and are responsible for about $20 \%$ of notifications. ${ }^{14}$ A common package design becomes an issue when purchasing many drugs from the same manufacturer. This becomes even more critical with injections, where ampoules and flasks may be similar in size, shape, and color, in general containing similarly colored solutions. Confusion may occur with greater frequency during emergencies and urgencies.

\section{Working environment and conditions}

An unfavorable working environment tends to increase dispensing error rates. The designated area for drug dispensing should have adequate space and appropriate lighting, temperature, and humidity for comfortable work. ${ }^{14}$ Drugs should be stored in a way that facilitates the workflow, and furniture should be ergonomically distributed. The most significant cause of dispensing errors in community and institutional pharmacies is work overload. Studies have demonstrated a direct relationship between errors and work overload. Stress caused by imposing a maximum time limit for dispensing the prescription is a significant factor. The most obvious solution for work overload is to have enough trained staff and to increase the time limit for dispensing the prescription. ${ }^{14}$

Lack of adequate training or supervision of pharmacy assistants also contributes to medication errors. Many Brazilian pharmacies have only one pharmacist, which means that the work of the pharmacy assistant goes mostly unsupervised and unchecked. Also, pharmacy assistants are usually trained in-service. Training courses in this area are recent and restricted to a few cities.

\section{Drug information}

Continuous technological development has led to frequent changes in information relating to drug use and safety. These changes have to be monitored by health professionals and applied in order for patients to benefit from them. It is a dangerous practice to use traditional or virtual books, outdated scientific magazines, Web sites, or other unreliable sources, all of which may yield incorrect information. ${ }^{14}$ Health professionals have an important role in patient education, and they should receive clear and safe information about drugs, ranging from their therapeutic and adverse effects to delivery times and routes. Users of medical drugs may become allies in preventing medication errors if they are well 
informed about the drugs being taken and can perceive errors not detected by health professionals, such as a dispensing error or a change in the delivery route. According to Cohen, ${ }^{14}$ patient counseling means additional safety against medication errors. Studies have shown that $83 \%$ of errors were discovered during interviews with patients and corrected before they had left the pharmacy.

\section{FINAL COMMENTS}

The pharmacy is an important link in the complex process of the use of drugs within a hospital. It permeates and interconnects many actions developed in different areas of this process. Its physical structure, human and technological resources, and organization according to state-of-theart standards for patient safety are essential for preventing and reducing medication errors.
The ever-growing worldwide pressure to overcome drug safety failures requires that health professionals and health institutions acquire elaborate knowledge of a variety of incidents that may occur during the process of drug use. A clear conceptual definition of such incidents allows us to seek knowledge about the true epidemiological force of each of thedetermining factors, which is essential for promoting change in posture and in defining preventive measures.

Although most dispensing errors may be classified as banal, they can reach significant epidemiological levels. Failures in the dispensing process mean that one of the last links in the safe use of drugs has been breached. Even though for the most part they do not cause harm to patients, the existence of dispensing errors reveals failures in the work process and directly points towards a higher risk of severe accidents.

\section{RESUMO}

Anacleto TA, Perini E, Rosa MB, César CC. Erros de medicação e sistemas de dispensação de medicamentos em farmácia hospitalar. Clinics. 2005;60(4):325-32.

A farmácia hospitalar permeia e interliga várias ações desenvolvidas em diferentes setores no complexo processo de utilização do medicamento dentro do hospital. Falhas na dispensação significam o rompimento de um dos últimos elos na segurança do uso dos medicamentos. Ainda que grande parte dessas falhas não cause danos aos pacientes, sua existência denuncia fragilidade no processo e indica, em uma relação direta, riscos maiores de ocorrência de acidentes graves. Os conceitos atuais dos incidentes relacionados a medicamentos podem ser categorizados em grupos e incluem as reações adversas, os eventos adversos e os erros de medicação. Dentre estes se inclui os erros de dispensação, cujas causas mais comuns se associam ao caráter inseguro e ineficiente dos próprios sistemas de dispensação. Os fatores associados a estes erros se resumem nas falhas de comunicação, nos problemas relacionados à rotulagem e embalagem dos medicamentos, na sobrecarga de trabalho e na estrutura da área de trabalho, nas distrações e interrupções, no uso de fontes de informação incorretas e desatualizadas e na falta de conhecimento e educação do paciente sobre os medicamentos que utiliza. O erro de dispensação, ainda que em muitos casos possa ser classificado como banal, assume níveis epidemiológicos importantes. Este artigo, parte de um estudo sobre a ocorrência de erros de dispensação na farmácia de um hospital geral de grande porte, visa divulgar uma revisão sobre os principais conceitos que hoje norteiam os estudos sobre eventos adversos, bem como o estágio atual do conhecimento sobre os erros de dispensação.

UNITERMOS: Erros de medicação. Erros de dispensação. Medicamentos. Farmácia Hospitalar. Eventos adversos.

\section{REFERENCES}

1. Sevalho G. Uma abordagem histórica das representações sociais de saúde e doença. Cad Saúde Pública. 1993;9(3):349-63.

2. Otero MJ, Domínguez-Gil A. Acontecimentos adversos por medicamentos: una patología emergente. Farm Hosp. 2000;24(4):258-66

3. Laporte JR, Tognoni G, Rosenfeld S. Epidemiologia do medicamento: princípios gerais. São Paulo: Hubitec;1989.264p.

4. Rosenfeld S. Farmacovigilância: elementos para a discussão e perspectivas. Cad Saúde Pública. 1998;14(2):237-63.
5. Manasse HR. Medication use in an imperfect world: drug misadventuring as an issue of public policy, part 1. Am J Hosp Pharm. 1989;46:929-44.

6. Manasse HR. Medication use in an imperfect world: drug misadventuring as an issue of public policy, part 2. Am J Hosp Pharm. 1989;46:1141-52.

7. Lazarou J, Pomeranz B, Corey PN. Incidence of adverse drug reactions in hospitalized patients: a meta-analysis of prospective studies. JAMA. 1998;279(15):1200-5. 
8. Kohn LT, Corrigan JM, Donaldson MS. To err is human: building a safer health system. Washington: National Academy of the Institute of Medicine;1999.-223p.

9. Phillips J, Beam S, Brinker A, Holquist C, Honig P, Lee LY, et al. Retrospective analysis of mortalities associated with medication errors. Am J Health Syst Pharm. 2001;58(19):1824-9.

10. Rosa MB, Perini E. Erros de medicação: quem foi? Rev Assoc Med Bras. 2003;49(3):335-41.

11. National Coordinating Council for Medication Error Reporting and Prevention - NCCMERP. Taxonomy of medication errors, 1998. (cited 2001 Dec 05); Available from: http:// www.nccmerp.org/aboutmederrors.htm.

12. American Society of Health-System Pharmacists - ASHP. Suggested definitions and relationships among medication misadventures, medication errors, adverse drug events, and adverse drug reactions, 1998. (cited 2001 Dec 05); Available from: http://www.ashp.org/ public/proad/mederror/.

13. World Health Organization. Requirements for adverse reaction reporting. Geneva: World Health Organization;1975.

14. Cohen MR. Medication errors. Washington: American Pharmaceutical Association;1999.

15. Flynn AE, Barker KN, Carnahan BJ. National observational study of prescription dispensing accuracy and safety in 50 pharmacies. J Am Pharm Assoc. 2003;43(2):191-200.

16. Ribeiro E. Dose unitária: sistema de distribuição de medicamentos em hospitais. Rev Adm Emp. 1993;33(6):62-73.

17. Gomes MJVM, Reis AMM. Ciências farmacêuticas: uma abordagem em farmácia hospitalar. São Paulo: Atheneu;2000. 560p.

18. Coordenação de Controle de Infecção Hospitalar do Ministério da Saúde [Brasil]. Guia básico para a farmácia hospitalar. Brasília: Ministério da Saúde;1994. 175 p.

19. Conselho Federal de Farmácia. Manual básico de farmácia hospitalar. Brasília: Conselho Federal de Farmácia;1997. 149 p.
20. Osório de Castro CGS, Castilho SR. Diagnóstico da Farmácia Hospitalar no Brasil. Rio de Janeiro: Fundação Oswaldo Cruz; 2004. $150 \mathrm{p}$

21. Leape LL, Kabcenell AI, Gandhi TK, Carver P, Nolan TW, Berwick DM. Reducing adverse drug events: lessons from a breakthrough series collaborative. Jt Comm J Qual Improv. 2000;25(6):321-31.

22. Barker KN, McConnel WE. The problem of detecting errors in hospitals. Am J Hosp Pharm. 1962;19:360-9.

23. Barker KN, Kimbrought W, Heller WM. A study of medication errors in hospital. Arkansas: University of Arkansas; 1966.

24. Barker KN. The effects of an experimental medication systems on medication errors and costs. I. Introduction and error study. Am J Hosp Pharm. 1969;26:324-33.

25. Crawley HK, Eckel FM, McLeod DC. Comparison of a traditional and unit dose drug distribution system in a nursing home. Drug Intell Clin Pharm. 1971;5:166-71.

26. Barker KN, Pearson RE, Hepler CD, Smith WE, Pappas KN. Effect of an automated bedside dispensing machine on medical errors. Am J Hosp Pharm. 1984;41(7):1352-8.

27. Barker KN, Allan EL. Research on drug-use-system errors. Am J Health Syst Pharm. 1995;52(4):400-3.

28. Carvalho VT, Cassiani SHB. Erros na medicação: análise das situações relatadas pelos profissionais de enfermagem. Medicina. 2000;33:322-30.

29. Faddis MO. Eliminating errors in medication. Am J Nurs. 1939;39(2):1217-23

30. Bueno E, Cassiani SHB, Miquelin JDL. Erros na administração de medicamentos: fatores de risco e medidas empregadas. Rev Baiana Enferm. 1998;11(1):101-19.

31. Otero MJ, Martín R, Robles MD, Codina C. Errores de medicación. Madrid: Farmacia Hospitalaria, 2002, 747p. 